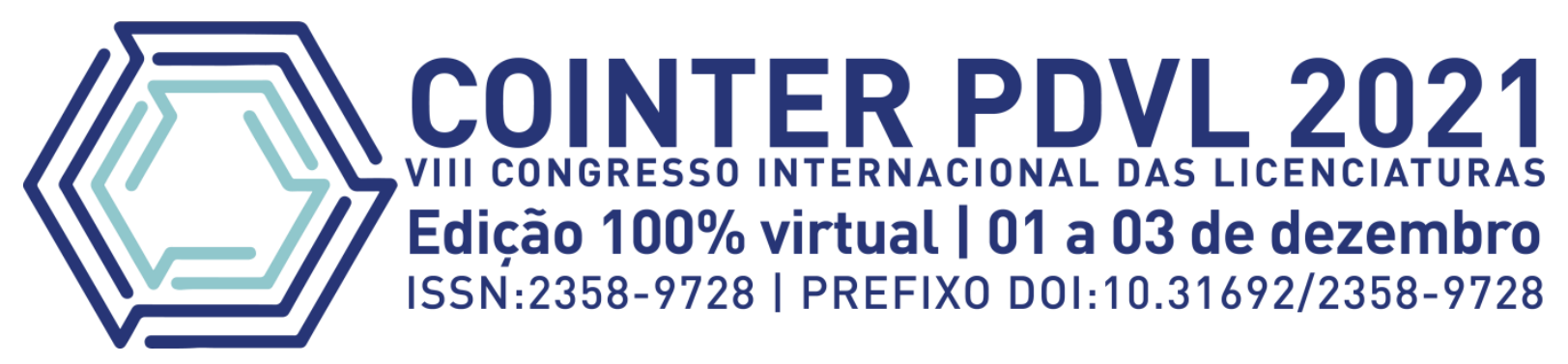

\title{
ANÁLISE DOS CONTEÚdOS DE FÍSICA MODERNA NO ENSINO MÉDIO: CONHECIMENTOS MÍNIMOS NO CURRÍCULO POR COMPETÊNCIAS
}

\author{
ANÁLISIS DE CONTENIDOS DE LA FÍSICA MODERNA EN LA ESCUELA \\ SECUNDARIA: CONOCIMIENTOS MÍNIMOS EN EL CURRÍCULO POR \\ COMPETENCIAS
}

\section{ANALYSIS OF CONTENTS OF MODERN PHYSICS IN HIGH SCHOOL: MINIMUM KNOWLEDGE IN THE CURRICULUM BY SKILLS}

\author{
Apresentação: Comunicação Oral \\ Inaiara Leite Rodrigues ${ }^{1}$; Ronaldo Coelho Pereira ${ }^{2}$;saiane Rocha Bezerra ${ }^{3}$; Lourenilson Leal de Sousa ${ }^{4}$
}

DOI: https://doi.org/10.31692/2358-9728.VICOINTERPDVL.0012

\begin{abstract}
RESUMO
O presente trabalho visa promover uma discussão acerca do currículo e dos conteúdos escolares de Física Moderna e Contemporânea (FMC) no Ensino Médio (EM). Neste sentido, ressalta-se que a inserção de FMC é um tema altamente debatido na literatura, em que é discutido, por exemplo, sobre a análise crítica do currículo, os documentos oficiais que orientam a educação básica, propostas didáticas e outras produções que visam a incorporação de tópicos de FMC no EM. A área de FMC é muito importante para o campo de pesquisas científicas, para o avanço tecnológico, para a medicina, dentre outros. Desta forma, progressivamente, vem sendo discutida a necessidade de abordá-la nos currículos da Educação Básica. Posto isto, o esboço do trabalho partiu de uma análise bibliográfica sobre o Ensino de FMC, em que teve como banco de dados o Portal de Periódicos da Capes e o Google Acadêmico, nos quais foram identificados trabalhos com diversidade nas fundamentações, nas temáticas socializadas, nas metodologias, entre outros aspectos. As análises dos documentos oficiais sobre o currículo escolar nas últimas décadas e na produção acadêmica sobre o tema evidenciaram uma diversidade de propostas de ensino do conteúdo da FMC no EM. Os resultados deste estudo mostram a existência de uma consistente produção acadêmica sobre o ensino de FMC e a necessidade de o currículo escolar ser ressignificado e compreendido na sala de aula, partindo de produtos educacionais, sequências didáticas
\end{abstract}

\footnotetext{
${ }^{1}$ Licenciatura em Física, Instituto Federal do Piauí, inaiaraleite68@gmail.com

${ }^{2}$ Licenciatura em Física, Instituto Federal do Piauí, ronaldocoelho18@gmail.com

${ }^{3}$ Licenciatura em Física, Instituto Federal do Piauí, rochaisaiane@ gmail.com

${ }^{4}$ Doutor, Instituto Federal do Piauí, lourenilson@ifpi.edu.br
} 
e projetos de pesquisa/extensão, que poderão aumentar a socialização dos conhecimentos da FMC, bem como auxiliar no desenvolvimento de habilidade e competências.

Palavras-Chave: Conteúdos Escolares; Física Moderna; Ensino de Física.

\title{
RESUMEN
}

Este trabajo tiene como objetivo promover una discusión sobre el plan de estudios y los contenidos escolares de la Física Moderna y Contemporánea (FMC) en la Escuela Secundaria (ES). En este sentido, se destaca que la inserción de la FMC es un tema muy debatido en la literatura, que se discute, por ejemplo, sobre el análisis crítico del currículo, los documentos oficiales que orientan la educación básica, propuestas didácticas y otras producciones dirigidas. en la incorporación de temas FMC en ES. Por tanto, el área de FMC es muy importante para el campo de la investigación científica, para el avance tecnológico, para la medicina, entre otros. Así, de manera progresiva, se ha discutido la necesidad de abordarlo en los planes de estudio de Educación Básica. Dicho esto, el esquema del trabajo partió de un análisis bibliográfico sobre la Didáctica de la FMC, en el cual se utilizó como base de datos el Portal Capes Journal y Google Academic, en el que se identificaron trabajos con diversidad en cuanto a fundamentos, en temas socializados, en metodologías, etc. El análisis de documentos oficiales sobre el currículo escolar en las últimas décadas y la producción académica sobre el tema mostró una diversidad de propuestas para la enseñanza de los contenidos FMC en ES. Los resultados de este estudio muestran la existencia de una producción académica consistente sobre la enseñanza de la FMC y la necesidad de que el currículo escolar sea redefinido y entendido en el aula, a partir de productos educativos, secuencias didácticas y proyectos de investigación / extensión, que pueden incrementar la socialización del conocimiento FMC, así como la asistencia en el desarrollo de habilidades y competencias.

Palabras Clave: Contenidos Escolares; Física Moderna; Enseñanza de la Física.

\begin{abstract}
This work aims to promote a discussion about the curriculum and school contents of Modern and Contemporary Physics (MCP) in High School (HS). In this sense, it is noteworthy that the insertion of $\mathrm{MCP}$ is a highly debated topic in the literature, which is discussed, for example, on the critical analysis of the curriculum, the official documents that guide basic education, didactic proposals and other productions aimed at the incorporation of MCP topics in HS. Therefore, the MCP area is very important for the field of scientific research, for technological advancement, for medicine, among others. Thus, progressively, the need to address it in Basic Education curricula has been discussed. That said, the outline of the work started from a bibliographical analysis on the Teaching of MCP, in which the Capes Journal Portal and Google Academic were used as a database, in which works with diversity in terms of foundations, in socialized themes were identified, in methodologies, etc. The analysis of official documents on the school curriculum in recent decades and academic production on the subject showed a diversity of proposals for teaching the MCP content in HS. The results of this study show the existence of a consistent academic production on the teaching of MCP and the need for the school curriculum to be redefined and understood in the classroom, based on educational products, didactic sequences, and research/extension projects, which may increase the socialization of MCP knowledge, as well as assisting in the development of skills and competences.
\end{abstract}

Keywords: School Contents; Modern Physics; Teaching Physics.

\section{INTRODUÇÃO}

O Ensino de Física no Brasil é uma área de pesquisa repleta de metodologias, estudos aplicados, ideias inovadoras que visam a divulgação científica e o desenvolvimento do saber, dentre outras finalidades. Quanto às áreas estudadas, destaca-se a área de proposta da inserção de Física Moderna e Contemporânea (FMC) no Ensino Médio (EM), tal proposta de inserção, 
por exemplo, é destacada no trabalho de Ostermann e Moreira (2000), em que trazem uma revisão de literatura referente ao tema de FMC, nos quais apontam alguns intuitos, como divulgação científica, elaboração de material de consulta para professores de educação básica etc.

Diante disso, a ideia de inserção da FMC é muito discutida na literatura. Essa idealização é problematizada e contextualizada desde as críticas do currículo escolar, livros didáticos, formação docente e o surgimento de metodologias para o desenvolvimento do conhecimento na área de FMC. Portanto, o Ensino de Física e suas linhas de pesquisas apontam para um campo de estudos com possibilidade de desenvolver os conhecimentos científicos juntamente com as habilidades e competências necessárias para formação discente na área da Ciências da Natureza e suas Tecnologias. Por isso, deve-se buscar desenvolver trabalhos que possam auxiliar os alunos na interpretação lógica da matemática, no conhecimento da contribuição dos estudos da física do século XX, organização de ideias e interpretação do mundo contemporâneo, devido ao crescente avanço da tecnologia, por exemplo.

Logo, as pesquisas sobre o Ensino de Física evidenciam a necessidade de divulgação dos conhecimentos científicos do campo da FMC. Portanto, torna-se relevante investigar e compreender as pesquisas na área da FMC, através das fundamentações e metodologias utilizadas pela comunidade acadêmica que trabalham com essa temática e analisar se estão em consonância com as habilidades e competências descritas nos documentos curriculares da educação brasileira e seus impactos.

Em síntese, compreende-se que no sentido da socialização e do ensino desses conhecimentos da FMC, há diversos estudos que investigam a maneira como os docentes e pesquisadores da área estão desenvolvendo esses conteúdos escolares nas salas de aula, de acordo com a realidade educacional do Brasil. Assim, possibilitando uma discussão sobre os temas introdutórios da FMC na educação, visto que estão presentes nos documentos curriculares. Assim, colaborando para compreensão e discussão acerca do currículo e dos conteúdos escolares do ensino de FMC no EM.

\section{FUNDAMENTAÇÃO TEÓRICA}

A Física Moderna também conhecida de Física do Século XX segue de uma trajetória, segundo Salinas (2010, p.369), registrada pela "relatividade, mecânica quântica, átomos e estados da matéria, o interior do núcleo atômico, os campos fundamentais e suas forças”. Vale salientar alguns nomes de cientistas, como Albert Einstein, Max K. E. L. Planck, Marie Curie e dentre outros, que foram essenciais para a construção dessa área. Sendo eles o ponto de partida 
para o conjunto de teorias que englobam a Física Quântica, Física Nuclear, Física de Partículas, dentre várias outras áreas da Física.

[...] Tais conhecimentos deram origem à Física Moderna, onde a Relatividade busca explicar os fenômenos em escalas astronômicas e a Mecânica Quântica em escala atômica. Já a Física Contemporânea tem origem após a Segunda Guerra Mundial, e estuda principalmente partículas subatômicas (DOMINGUINI; MAXIMIANO; CARDOSO, 2012, p.1).

Os conhecimentos que deram origem à Física Moderna possibilitaram o entendimento e a interpretação dos fenômenos que ocorrem na natureza. Assim, os avanços que surgiram após esses conjuntos de teorias reforçam que é indiscutível a importância da sua inserção no ensino básico, na sala de aula e em livros didáticos, e é imprescindível no processo formativo do professor, logo:

O desenvolvimento da FMC trouxe diversas inovações conceituais que modificaram a maneira de interpretar muitos dos fenômenos do Universo. Por exemplo, a Relatividade Geral traz uma nova interpretação de tempo e espaço, além da proposição da existência de buracos negros. Já a Mecânica Quântica se volta para o mundo do muito pequeno, e seus resultados abalam as bases do "determinismo" clássico; as partículas podem se comportar como ondas e as ondas, como partículas (KIKUCHI et al., 2013, p.1).

Posto isso, nas últimas décadas pesquisadores, tais como Moreira (2018) e Osterman (2000), vêm propondo a necessidade de inserção dos conhecimentos de FMC na educação básica, visando sua relevância para uma sociedade que esteja alfabetizada em um contexto científico e técnico, conhecida como Alfabetização Científica e Técnica (ACT). De acordo com Fourez (1997, p.15 apud LEONEL, 2009), a expressão ACT surge como uma metáfora à alfabetização do final do século XIX, designando um tipo de saber, de capacidade ou de competência para o mundo técnico científico.

Diante dessa premissa, a inserção assume um papel importante no processo de ensinoaprendizagem do aluno. Portanto, o Ensino de FMC em suas diferentes temáticas pode proporcionar meios acessíveis que corroboram para expandir o conhecimento desta área em diferentes contextos. Dessa forma, é possível evidenciar que "a Física permeia a vida dos seres humanos" (MOREIRA, 2018, p.76), assim, assumindo um papel fundamental para explicar o mundo físico, e compreender que a ciência não é uma área isolada, mas que está presente na sociedade como um todo, por exemplo, na utilização de nanotecnologia (utilizada em displays de telefonia celular). Sendo assim, é necessário que compreendam a Física como uma ciência que faz parte do contexto cultural, científico, social e dentre outros, assim é necessário: 
[...] despertar a curiosidade dos estudantes e ajudá-los a reconhecer a física como um empreendimento humano e, portanto, mais próxima dos estudantes; estabelecer o contato dos alunos com as ideias revolucionárias que mudaram totalmente a Ciência do século XX; atrair jovens para a carreira científica, futuros pesquisadores, professores (PENA, 2006, p.1).

Diante disso, espera-se que os trabalhos que abordem essa temática contextualizem de modo sucinto suas metodologias/propostas, aplicações e resultados. A literatura científica apresenta inúmeros trabalhos que evidenciam metodologias de Ensino de Física em diferentes cenários, sempre reforçando a importância da inserção da FMC no EM. Logo, analisar as metodologias dessas pesquisas é importante, visto que o Ensino de Física na educação básica é defendido pelos Parâmetros Curriculares Nacionais (PCN 's) + Ensino Médio, pois, entende-se que essa prática é essencial para o desenvolvimento de um cidadão contemporâneo, assim:

[...] alguns aspectos da chamada Física Moderna serão indispensáveis para permitir aos jovens adquirir uma compreensão mais abrangente sobre como se constitui a matéria, de forma a que tenham contato com diferentes e novos materiais, cristais líquidos e lasers presentes nos utensílios tecnológicos, ou com o desenvolvimento da eletrônica, dos circuitos integrados e dos microprocessadores (BRASIL, 2002, p.19).

Percebe-se nos PCN + Ensino Médio que a ideia de inserção de FMC é interpretada de forma positiva, em que compreende que os jovens devem estar cientes sobre a influência da FMC no desenvolvimento de tecnologias e compreensão da matéria dentre outros tópicos importantes. Além disso, é importante mencionar que as orientações expostas nos PCN 's, trazem como objetivos/metas o desenvolvimento de habilidades e competências, como, competência de investigação e compreensão.

Lembrando que a definição de competência tem um marco nas discussões pedagógicas e sociais, visto que na Base Nacional Comum Curricular (BNCC) é definida como "mobilização de conhecimentos (conceitos e procedimentos), habilidades (práticas, cognitivas e socioemocionais), atitudes e valores [...]" (BRASIL, 2017, p.8). As competências e habilidades estão descritas de forma geral na BNCC, com o objetivo de determinar um conjunto de orientações essenciais no processo de aprendizagem, em que todos os alunos devem desenvolver ao longo da sua trajetória escolar, em todos os níveis da educação básica, assim, tais habilidades e competências assumem como requisito fundamental na reelaboração de projeto políticos pedagógicos das escolas, pois: 
O currículo do ensino médio será composto pela Base Nacional Comum Curricular e por itinerários formativos, que deverão ser organizados por meio da oferta de diferentes arranjos curriculares, conforme a relevância para o contexto local e a possibilidade dos sistemas de ensino, a saber: [...]. § $1^{\circ}$ A organização das áreas de que trata o caput e das respectivas competências e habilidades será feita de acordo com critérios estabelecidos em cada sistema de ensino (BRASIL, 2017, p.25).

Nessa perspectiva, o currículo é importante para construção social e formação cidadã do discente, pois, entende-se que "a visibilidade da linguagem em um currículo de ciências cria possibilidades para discutir o papel do discurso no ensino nos vários contextos de construção do currículo" (FRANCO; MUNFORD, 2018, p. 164). Diante das reflexões sobre a BNCC, PCN 's + Ensino Médio e as propostas de currículo entende-se que a educação científica no contexto do EM caracteriza-se por aspectos de desenvolvimento de capacidade e habilidades. Que deverão ser construídas a partir dos conteúdos dispostos nos livros didáticos e com os desenvolvimentos de projetos que devem ser adicionados às diretrizes escolares.

Diante disso, a BNCC e seus itinerários formativos (conjunto de disciplinas, projetos, oficinas etc.) são alvos de críticas sejam elas construtivas ou destrutivas, à custa de ser um documento normativo em que define um conjunto orgânico e progressivo de aprendizagens (BRASIL, 2017). Assim, formam linhas de pesquisas sobre seus impactos no EM, por constituir um documento que assegura a formação do discente, logo, os autores, evidenciam:

\footnotetext{
[...] se furta dessas discussões e está focada em listas de conteúdos e competências. Termos como "desenvolver", "participar", "cuidar", "relacionar", "debater", "produzir", "apropriar-se" na BNCC, mostram um panorama vazio de significado. A impressão que fica, principalmente com relação aos objetivos de aprendizagem, é sua clara utilidade para fins de avaliação e produção de material didático (MOZENA; OSTERMANN, 2016, p. 331).
}

A ideia do autor condiz com outras críticas encontradas na literatura, por exemplo, Selles (2018) e Tenfen (2016), em que ambos trazem uma análise crítica e reflexiva sobre a BNCC e seu impacto no ensino. A atualização da BNCC tornou-se um assunto discutido em todos os níveis de ensino, por causa disso, possibilitou denotar pontos positivos e negativos desse "novo" processo que os estudantes estarão incluídos.

Nesse contexto, cabe avaliar a intercessão entre a BNCC e o Ensino de Física. Os autores Mozena e Ostermann (2016) apontaram alguns pontos importantes sobre essa conjuntura, eles mencionam que apesar das discussões e tendências acerca das teorias e propostas curriculares no Brasil a BNCC ainda é marcada por um perfil de "hibridização", e que a pesquisa no Ensino de Física está longe de se incorporar nessas discussões, devido à ausência de tradição aos estudos sobre políticas públicas na área. Logo, a BNCC tende a acarretar impactos 
significativos na educação, e suas versões podem gerar consequências em linha de retrocesso ou progresso. Por isso, ressalta-se que a nova versão pode trazer um déficit no Ensino de Física, principalmente na área de Física Moderna, como destaca Mozena e Ostermann (2016) ao apontarem que haveria uma concepção positiva na primeira versão apresentada do texto da BNCC, mas que foi eliminada na segunda versão, com ênfase no estudo da Física Moderna e o uso da História da Ciência, portanto, apontando apenas versões já existentes.

Em síntese, os conhecimentos e teorias do campo da FMC são inseridos nos parâmetros que regem o ensino na educação básica. No entanto, a maneira como é ensinada e para que ensinar, ou seja, desde a escolha dos conteúdos que serão socializados na sala de aula considerando o tempo-espaço da aula e conhecimentos prévios dos estudantes - será necessário que o/a professor (a) intérprete as determinações dos currículos oficiais.

\section{METODOLOGIA}

Para a elaboração desse trabalho desenvolve-se a seguinte metodologia de pesquisa: buscar por produções mais recentes que trabalham com a temática de FMC no EM no período de 2009 a 2019, pois, toma-se como base outros trabalhos com temática semelhante, como de Pereira e Ostermann (2009) que trabalharam com a revisão da temática de FMC entre os anos de 2001 - 2009; definir os tópicos de FMC, ou temas dos trabalhos analisados; classificação dos trabalhos que apresentam resultados de pesquisas aplicadas, propostas didáticas e sequência didáticas, com o tema central no ensino de FMC.

Utilizando como ferramenta de busca o Portal Periódico da Capes e o Google Acadêmico para a consulta, a pesquisa bibliográfica teve como ênfase as publicações relacionadas ao ensino de FMC, para tanto foram utilizadas as seguintes palavras-chave: “Ensino de Física Moderna no Ensino Médio", "Efeito Fotoelétrico”, “Teoria da Relatividade para o Ensino Médio", "Simulação para Ensino de FMC no Ensino Médio”, "Inserção de FMC”, "Proposta/sequência para Ensino de FMC para o Ensino Médio", "Experimentação do Ensino de FMC no Ensino Médio", "Metodologias no Ensino FMC", evitando assim outros artigos, e diminuindo os resultados de artigos com que tratam sobre a Física em geral.

Com base na metodologia adotada, foram selecionados 20 (vinte) trabalhos que se enquadram no interesse da pesquisa citado anteriormente. Assim, partindo de uma pesquisa de natureza qualitativa que tem como propósito a investigação dos conteúdos e temáticas sobre o ensino de FMC, com base PCN 's, BNCC na produção acadêmica (artigos). Do ponto de vista operacional, a análise partiu de uma leitura de primeiro plano dos documentos oficiais que orientam a prática docente com o Ensino de FMC. Em seguida, os artigos passaram por uma 
leitura flutuante-reflexiva e foi feita uma análise textual-discursiva em relação aos temas e conteúdos escolares de FMC para compreensão sobre a maneira como a produção acadêmica faz a recontextualização do currículo oficial.

Utilizou-se da abordagem de Análise Documental, tal método permitiu a elaboração de sentidos e interpretações sobre a temática do ensino da FMC no Ensino Médio, pois, este visa a "representação condensada de informação para consulta [...]" (BARDIN, 1997, p. 46), seguindo de uma análise de conteúdo que pode ser entendido como "manipulação de mensagem (conteúdos e expressões desse conteúdo), para evidenciar os indicadores que permitem inferir sobre outra realidade [...]" (BARDIN, 1997, p.46).

\section{ANÁLISE BIBLIOGRÁFICA DA TEMÁTICA NO ENSINO DE FMC: DESCRIÇÕES DOS TRABALHOS}

A literatura apresenta uma ampla diversidade de tópicos de FMC, divididos em diferentes temáticas e métodos, por exemplo, na utilização de sequência didática, como um produto confeccionado para abordar a FMC. Diante disso, destaca-se o trabalho de Merlim et al. (2019), em que implementaram uma sequência didática para alunos de $2^{\circ}$ ano do EM, em uma escola estadual, no município de São Sebastião do Alto/RJ, com o objetivo de compreender e reconhecer sobre efeito fotoelétrico, natureza corpuscular da luz e reforçando a importância da FMC. O trabalho baseou-se no uso da Unidade de Ensino Potencialmente Significativa (UEPS) elaborado por Moreira (2011) e no uso de metodologias ativas. Obtiveram resultados satisfatórios, pois conseguiram tornar os alunos ativos na construção do seu próprio conhecimento, pelo resultado eficiente que os professores tiveram na aplicação da UEPS.

Com a mesma base teórica da UEPS, Martins et al. (2017), utilizaram para a inserção do tópico de Relatividade Restrita, fazendo uma comparação com aulas tradicionais. A proposta foi executada em duas escolas estaduais localizadas na cidade de Capitão Leônidas MarquesPR. Abordaram em seu trabalho a UEPS e a aulas tradicionais, aplicando em seguida um questionário intitulado "pré-teste" e "pós-teste" composta por 60 questões que eram dividas tópicos: 1) referencial inercial; 2) invariância da velocidade da luz; 3) dilatação temporal; 4) contração do comprimento com abordagem conceitual, procedimental e aplicação da ciência; 5) simultaneidade de eventos com cunho conceitual e procedimental. Em seguida fez uma análise estatística inferencial comparando qual método é mais facilitador da Aprendizagem

Significativa baseando nas fundamentações Ausubel, logo, concluíram que UEPS foi mais significativa que as aulas tradicionais. 
Seguindo com o UEPS, Schitter e Moreira (2016) trabalharam com a introdução de FMC, seguindo com fundamentos em teorias da aprendizagem e o modelo da UEPS como base para a introdução do tópico de FMC com o tema Laser de Rubi. O intuito era desenvolver: compreensão do modelo atômico de Bohr e o princípio de conservação do momento angular, quantização da energia, diagrama de níveis de energia para o átomo de hidrogênio, inversão de população para então entrar com o efeito Laser e Laser de Rubi. Desenvolvendo metas definidas: tarefa inicial; situação problema; aprofundamento de conhecimento; nova situação problema; aula expositiva; e avaliação de aprendizagem. Tais procedimentos possibilitaram a aprendizagem e concluíram que é possível inserir tópicos de Física Moderna e Contemporânea para alunos do primeiro ano do EM partindo da metodologia aplicada.

Esses autores trabalharam com o embasamento em UEPS de diferentes cenários, e ambos notaram resultados satisfatórios para a utilização dessas metodologias tanto para o Ensino de Efeito Fotoelétrico (EF) e outras temáticas que fazem parte do Ensino de FMC. Mas é necessário ressaltar que a fundamentação partiu dos pressupostos: metodologias ativas; aprendizagem significativa; comparação de metodologias, logo é possível averiguar que trazem resultados e discussões positivistas diante das práticas utilizadas.

Há outras práticas, tal como, as Sequências Didáticas (SD) que estão inseridas com embasamentos teóricos capazes de dar significados para diferentes métodos, por exemplo, Batista e Siqueira (2017) que fundamentaram em seu trabalho o uso de Sequência de EnsinoAprendizagem (SEA) e Pesquisa Baseada em Projeto. Propôs a abordagem do tópico de radioatividade para as turmas do curso de Segurança do Trabalho e Técnico de Informática. Os resultados obtidos foram significativos, ressaltando que a medida utilizada (SEA) foi importante para a construção do conhecimento dos alunos, além de promover a habilidade de escrever e obter conhecimentos compatíveis com os apresentados na literatura. Assim, contribuindo para a argumentação da importância da atualização curricular, por meio da inserção da FMC, com intervenções práticas nos ambientes reais de sala de aula, desenvolvendo uma aprendizagem técnica-científica.

Seguindo o eixo da SD, Silva (2018) abordou a metodologia de Sala de Aula Invertida proposta por Lage, Platt e Treglia. Inicialmente, o material é disponibilizado pelo professor antes da aula, e na aula seguinte as atividades são divididas da seguinte forma: resolução de problemas; discussões de tarefas; realização de experimentos; fases de projetos; esclarecimento de dúvidas. O tema abordado foi a dilatação temporal da Relatividade Restrita. O professor forneceu texto com exemplificação conceitual dentre outros materiais que compõem a metodologia da sala de aula invertida, mas ressalta que não foi um trabalho fácil devido ao 
excesso de fórmulas presentes nos textos, e isto poderia dificultar o entendimento dos estudantes. Ao aplicar essa metodologia o docente propõe aos alunos algumas atividades, tais como, produção de vídeos e texto científico, com o intuito de identificar nos discentes o desenvolvimento de linguagem científica em relação às aulas tradicionais.

Diante do contexto, surge também às Propostas Didáticas (PD) que são facilmente encontradas na literatura, por exemplo, para o Ensino de EF, a fim de auxiliar os docentes na sua prática dentro da sala de aula, como proposta por Muniz et al. (2018), em que trabalharam na produção de uma proposta metodológica: Utilização de experimentação de baixo custo e o uso de recursos tecnológicos. A fundamentação parte da importância do Ensino de EF e a utilização das Tecnologias da Informação e Comunicação (TIC 's). Argumentaram que esse tipo de atividade pode ser significativa, pois desperta o interesse nos alunos em relação ao tema, assim discorre todos os procedimentos e como aproveitar cada detalhe dessa metodologia em favor do desenvolvimento do conhecimento.

Seguindo o mesmo eixo temático do Ensino de EF, destaca-se o trabalho de Eberhardt et al. (2017) no qual elaboram uma proposta destinada ao ensino de EF, em que tem como objeto de estudo: o conceito histórico do EF; característica de experimento; a função do trabalho dos metais. Destacaram a importância da inserção de FMC, diante da evolução tecnológica, advindos dos conceitos físicos científicos. A proposta é um protótipo de experimentação do $\mathrm{EF}$ destinada ao EM composta de uma abordagem teórico-histórica, bem como a explicação dos fenômenos ocorridos. São citados seis objetivos que o discente deve alcançar após a experimentação. A expectativa é que os docentes de Física utilizem dessa prática nas aulas, pois faz parte da temática do contexto de FMC que é exigido com frequência nos vestibulares e no ENEM.

Entre outros os métodos didáticos, encontra-se a utilização da experimentação, como o aplicado por Melhorato e Nicoli (2012) que, inicialmente, partiram da fundamentação da eficácia do uso de experimentação para o ensino-aprendizagem. Em seu trabalho abordaram os conteúdos de quantização de energia, modelo corpuscular da luz e condução de eletricidade em sólidos. Propondo como uma ferramenta de apoio para os docentes para abordagem de tópicos essenciais de FMC para o EM. Finalmente, fundamenta sobre a teoria, a montagem, o funcionamento e sugestões de abordagem do experimento.

Paralelamente, destaca-se na literatura os trabalhos que utilizam simulação computacional, programação etc., salientando como métodos atuantes para fins educacionais. Como destaca, Silveira e Girardi (2017) que abordaram tecnologia computacional como alternativa metodológica para auxiliar na elaboração de protótipos para experimentação. 
Inicialmente, introduziram a plataforma Arduino, fundamentando que constitui de uma programação relativamente fácil e com grande quantidade de informações. O trabalho descreve o desenvolvimento em 3 etapas: (1) montagem e funcionamento do dispositivo, (2) aplicação do kit no estudo EF, e incluindo exemplo de aplicação para demonstração de efeito termiônico e da condutividade elétrica do plasma e (3) conclusões e perspectivas. Tais procedimentos resultaram na construção do experimento interativo Kit Fotoduino, com o auxílio da plataforma de desenvolvimento, em que é aliada a uma interface gráfica. Com a perspectiva que o uso dessa moderna tecnologia seja um ambiente de aprendizagem para os alunos.

Com o mesmo método de utilização de tecnologia, encontra-se Soares et al. (2015), na qual utilizaram da perspectiva sociointerativa de Vygotsky para a fundamentação de sua análise. O trabalho traz a utilização do computador e de simuladores interativos para abordar os tópicos de espectroscopia, radioatividade e física nuclear. Essa abordagem resultou na eficácia da metodologia, tal que, possa ser útil para auxiliar no processo de ensino, bem como despertar o interesse e compreensão. Ressaltam-se os benefícios do uso da tecnologia para fins educativos e da metodologia. Nota-se que o trabalho se baseou nas Diretrizes Curriculares Nacionais para o EM para fundamentar a simulação, pois o uso de simulações poderá simular as situações da vida real.

Nota-se a presença do uso de experimentação com a utilização de tecnologias com o intuito de potencializar a metodologia abordada. Essa notabilidade pode ser vista como recurso em prol da educação, em que se cria uma expectativa na melhoria no Ensino de Física. Bem como na elaboração de proposta/sequência/metodologias para abordagem de diferentes temas, auxiliando o professor na sua prática em sala de aula.

Similarmente, há na literatura o uso de ferramenta de modelização, por exemplo, o aplicado por Lopes et al. (2017), onde trabalharam com uma ferramenta de modelização a fim de envolver os alunos na discussão de modelos atômicos e sobre a luz (Newton e Huygens). Usando como fundamentação a utilização da modelagem, surgindo assim, o mecanismo de ligação entre outras dimensões no processo de aprendizado. O método utilizado resultou positivamente, visto que os alunos conseguiram desenvolver o domínio da definição, do modelo de luz, bem como dos modelos científicos. Buscaram abordar de modo mais simplificado os conceitos físicos, utilizando da modelagem para abordar as partes teóricas e ilustrativas desenvolvendo a capacidade de interpretação dos conceitos e ilustrações científicas. Junto com a sequência didática foi confeccionado um protótipo da caixa preta elaborado por alunos, com o intuito de incentivar a pesquisar, investigar os conceitos físicos abordados, e em seguida 
levaram em discussão. Essa metodologia os levou a desenvolver a habilidade de investigação e conhecimento, tais habilidades são descritas na BNCC.

Outro método é a contextualização da FMC com o cotidiano, como abordam os autores Schreiber, et al. (2016) teve como foco buscar a física para sociedade abordando o tema de raio -X, uma prática utilizada na medicina. No trabalho, buscaram desenvolver atividades contextualizando, explicando o fenômeno e por último a aplicação. Na metodologia abordada foi possível instigar os alunos a entender sobre o fenômeno, bem como ter o conhecimento científico que ao atrelarem aos benefícios e malefícios da utilização dos raios-X. Tais procedimentos levaram os alunos a desenvolver habilidades de arguições orais para defender suas concepções, inserindo os discentes em campo de discussão de conhecimentos científicos.

Similarmente, voltado para o cotidiano, Silva e Sales et al. (2018) elaboram um projeto temático com abordagem da Relatividade Restrita e GPS. O intuito era investigar como os alunos constroem seus conhecimentos a partir da relação da interação dos tópicos, ressaltando a importância do GPS e sua relação com tecnologia e FMC. Foram aplicadas 8 aulas com abordagem histórica, conceitual e contemporânea, possibilitando uma metodologia que resultou na habilidade de construção de um novo conhecimento articulado com o cotidiano, dando significado para a teoria e interligando de forma contextualizada entre ciência e tecnologia em favor da sociedade.

Da mesma natureza, destaca-se o trabalho de Shiino et al. (2013), em sua pesquisa basearam-se nas propostas do PCN + Ensino Médio com intenção de dar significados para a aprendizagem adquirida. A sua proposta tinha como eixo principal: (I) Energia, Energia Nuclear e Física de Partículas; (II) implicações socioambientais, científica e tecnológica, com o intuito dos discentes se familiarizarem com o saber científico. Em seguida, abordaram nas aulas as questões de natureza socioambiental, política e econômica, trazendo como exemplo a utilização das usinas termonucleares e suas interferências no meio ambiente, podendo citar o lixo atômico produzido. Esse tipo de trabalho torna-se significativo, uma vez que, os discentes adquiram conhecimentos sobre a importância do saber científico e suas contribuições para a sociedade moderna.

Com método de criatividade, destaca-se Caruso e Freitas (2009) que realizaram por meio do projeto "Oficina de Educação através de Histórias em Quadrinhos e Tirinhas" EDUHQ um trabalho visava abordar através de tirinhas os conceitos de espaço-tempo, processo históricos de Einstein e dentre outros assuntos importantes sobre a relatividade. Assim, a metodologia proposta é: a elaboração das tirinhas, interação dos alunos com orientador, por fim a leitura de texto relacionado ao tema e criação das tirinhas. Para que isso acontecesse era 
necessário que os alunos entendessem os conceitos físicos, tornando assim alunos/artistas mostraram que tiveram o domínio em criar um diálogo. Por fim, concluíram que essa abordagem tem um caráter lúdico e pode ser utilizada como instrumento de apoio pelos professores.

Por conseguinte, a criatividade está presente na elaboração de métodos e proposta para o ensino. Assim, possibilitando a utilizando da interdisciplinaridade, logo, destaca-se a proposta de SD do Gomes et al. (2010), que abordaram em seu trabalho a interdisciplinaridade de duas áreas de conhecimento, a Física e a Literatura, partindo da análise da obra A Máquina do Tempo de H. G. Wells. Foi elaborada uma discussão referente ao tema para abordagem da teoria da relatividade, utilizando uma obra literária de ficção científica para o levantamento de discussão sobre questões de equívocos historiográficos, bem como desenvolver pensamento crítico a partir da criação de um espaço dialógico, como discutir os conceitos sobre o espaço-tempo, e despertar nos alunos o senso crítico e imaginário do educando em relação aos fenômenos relativísticos.

Diante do contexto, encontra-se o trabalho de Ramos e Piassi (2017), no qual elaboraram uma interdisciplinaridade entre Física e Literatura. Em seu trabalho abordaram as obras de contos fantásticos para trabalhar com a FMC, utilizando as obras de Edgar Allan Poe e as conquistas científicas; Jorge Luís Borges e os multiuniversos; Murilo Rubião e os estados quânticos. Utilizando da análise de estudo literário das obras a partir da semiótica greimasiana. Foram feitas as argumentações referentes às obras destacando ao final, visto isso, foi possível observar que os conceitos e temas referentes à Física estavam próximos da fantasia e da ficção criando um ambiente de hesitação entre o real e o sobrenatural. Ressalta-se que essa prática foi uma implementação de um projeto de clube de leitura científica que resultou no trabalho de estudo da leitura e sua relação com a Física.

Similarmente, encontra-se o trabalho de Gomes (2011). O autor argumenta sobre a utilização de obras literárias no contexto de ensino-aprendizagem, com uma proposta de abordar a interdisciplinaridade entre a Literatura e o Ensino de Física. Em seu trabalho abordou o tema da relatividade restrita de Albert Einstein com as seguintes obras de ficção: Sonhos de Einstein; Tau zero; O tempo do espaço do Tio Albert. Utilizando a referência linguística e linguística de análise, apontando os pontos que podem ser trabalhados em cada obra, argumenta que essa aplicação contempla, por exemplo, uma reflexão dos aspectos conceituais que permeiam a Teoria da Relatividade Restrita.

Além disso, na literatura encontram-se trabalhos como o de Júnior e A. Cristiane (2013) que partiram de com um método diferencial. Observando a inserção de FMC a partir de 
educação formal e não formal e sobre fundamentação de Sequência de Ensino e Aprendizagem - SEA com o intuito da inovação curricular. Os autores apresentaram uma atividade desenvolvida com parceria com professores atuantes na educação básica. Com a temática da física solar, os professores e pesquisadores elaboraram uma (SEA). Ressaltaram que essa prática visa à inovação curricular, pois a sua inclusão em um processo de investigação baseado no processo evolutivo gradual ligando o conhecimento científico à perspectiva do estudante $\mathrm{e}$ as ações docentes.

A diversidade na abordagem da FMC proporciona o desenvolvimento de trabalhos como, por exemplo, Pagliarini e Almeida (2014), elaboraram um trabalho que partiu de um projeto de extensão, que resultou em uma abordagem com o tema de Noções do Início da Física Quântica para alunos do E M. As atividades são baseadas com ênfase na leitura de textos científicos, a fim de aproximar os discentes à prática de leitura de texto produzida por cientistas com uma linguagem técnica. Utilizaram da fundamentação da Análise do Discurso para obter informações, e com essa metodologia, notaram as dificuldades na interpretação da leitura, já que o texto de divulgação científica não é trabalhado em sala de aula, por exemplo, o texto "Física Quântica: o estranho comportamento do mundo microscópico". Ou seja, essa prática necessita da mediação do professor levando, assim, a interação com o discente. Isto é, novas vias de acesso ao conhecimento na Física, levando o discente a desenvolver a habilidade de interpretação.

\section{RESULTADOS E DISCUSSÃO}

Diante das indagações sobre o Ensino de Física, destaca-se, Moreira (2018) em que disserta em seu trabalho uma análise crítica do Ensino de Física no Brasil com ênfase em várias áreas de pesquisas e menciona os desafios do ensino na educação contemporânea, reforçando a atualização do currículo de Física no Ensino Médio na qual defende a incorporação de tópicos de FMC, mas não conteudistas, e sim que sejam ensinados de forma contextualizada e atualizada conforme a realidade e contexto do cotidiano do aluno.

Um fato intrigante é que o discurso sobre a inserção de FMC ultrapassa décadas, tornando-se foco dos trabalhos relacionados a FMC em diferentes contextos, como descrito anteriormente. É notório que a FMC no EM tornou-se uma linha de pesquisa e estudo específico dentro do Ensino de Física. Salientando que a pesquisa sobre a FMC se desenvolveu após a década de 1980, em que vários fatores levaram ao seu surgimento, como, os questionamentos sobre a inserção da FMC e a desatualização do currículo (SILVA e ARENGHI et al, 2013).

Os trabalhos descritos na subseção anterior foram desenvolvidos a partir de 
fundamentações teóricas que justificam suas abordagens e seus objetivos. De modo geral, buscando uma transposição didática através de uma linguagem facilitadora, dinamizada, e dentre outros aspectos. Assim, visualizando o quadro 1, observa-se a diversidade dos trabalhos com diferentes tópicos de FMC.

Quadro 1: CRONOLÓGICO /ANO DE PUBLICAÇÃO

\begin{tabular}{|c|c|c|c|}
\hline $\mathrm{N}^{\mathrm{o}}$ & Ano & Autores & TÍTULO \\
\hline 01 & 2009 & $\begin{array}{l}\text { CARUSO, F; } \\
\text { FREITAS, N de. }\end{array}$ & $\begin{array}{l}\text { Física moderna no ensino médio: o espaço-tempo de } \\
\text { Einstein em tirinhas }\end{array}$ \\
\hline 02 & 2010 & GOMES, E. F. et al. & $\begin{array}{l}\text { A máquina do tempo de H.G. WELLS: uma } \\
\text { possibilidade de interface entre ciência e literatura no } \\
\text { ensino de física }\end{array}$ \\
\hline 03 & 2011 & GOMES, E.F. & $\begin{array}{l}\text { O romance e a teoria da relatividade. a interface entre } \\
\text { a literatura e ciência no ensino de física através do } \\
\text { discurso e da estruturação da ficção. }\end{array}$ \\
\hline 04 & 2012 & $\begin{array}{l}\text { MELHORATO, R. L; } \\
\text { NICOLI, G. T. }\end{array}$ & $\begin{array}{l}\text { Da física clássica a moderna: o simples toque de uma } \\
\text { sirene }\end{array}$ \\
\hline 05 & 2013 & SHIINO, H. S. et al. & $\begin{array}{l}\text { Uma proposta para sala de aula sobre a física nuclear e } \\
\text { a física de partículas. }\end{array}$ \\
\hline 06 & 2013 & $\begin{array}{l}\text { JUNIOR, P. C; A. } \\
\text { CRISTINA, C. C. S. }\end{array}$ & $\begin{array}{l}\text { Parceria entre a educação formal e não formal visando } \\
\text { inovações curriculares: o ensino de física moderna a } \\
\text { partir da física solar }\end{array}$ \\
\hline 07 & 2014 & $\begin{array}{l}\text { PLAGLIANIRI, C R; } \\
\text { ALMEIDA, M. J. P. M. }\end{array}$ & $\begin{array}{l}\text { Produção de sentidos numa leitura de divulgação } \\
\text { científica sobre física quântica no ensino médio }\end{array}$ \\
\hline 08 & 2015 & SOARES, et al. & $\begin{array}{l}\text { Ensino de matéria e radiação no ensino médio com o } \\
\text { auxílio de Simuladores interativos. }\end{array}$ \\
\hline 9 & 2016 & $\begin{array}{l}\text { SCHITTER, DANIELA } \\
\text { E MOREIRA, M. A. }\end{array}$ & $\begin{array}{l}\text { Física moderna e contemporânea no Primeiro ano do } \\
\text { ensino médio: laser de Rubi um exemplo de unidade } \\
\text { de ensino potencialmente significativa. }\end{array}$ \\
\hline 10 & 2016 & SCHREIBER, et al. & $\begin{array}{l}\text { Desenvolvendo atividades sobre a produção de raios- } \\
\text { X em aulas de Física no ensino médio }\end{array}$ \\
\hline 11 & 2017 & MARTINS, C. O. et. al & $\begin{array}{l}\text { O ensino de relatividade restrita no ensino médio a } \\
\text { partir de uma Unidade de Ensino Potencialmente } \\
\text { Significativa. }\end{array}$ \\
\hline 12 & 2017 & LOPES, E.V. et. Al & $\begin{array}{l}\text { Como se aproximar do invisível: o uso dos Modelos } \\
\text { no ensino da física moderna para alunos de ensino } \\
\text { médio }\end{array}$ \\
\hline 13 & 2017 & $\begin{array}{l}\text { BATISTA, C A.; } \\
\text { SIQUEIRA, M. R. P. }\end{array}$ & $\begin{array}{l}\text { A inserção da física moderna e contemporânea em } \\
\text { ambientes reais de sala de aula: uma sequência de } \\
\text { ensino-aprendizagem sobre a radioatividade. }\end{array}$ \\
\hline 14 & 2017 & EBERHARDT, D et al. & $\begin{array}{l}\text { Experimentação no Ensino de Física Moderna: efeito } \\
\text { fotoelétrico com lâmpada néon e LEDs. }\end{array}$ \\
\hline 15 & 2017 & $\begin{array}{l}\text { SILVEIRA, SÉRGIO; } \\
\text { GIRARDI, MAURICIO }\end{array}$ & $\begin{array}{l}\text { Desenvolvimento de um kit experimental com Arduino } \\
\text { para o ensino de Física Moderna no Ensino Médio. }\end{array}$ \\
\hline 16 & 2017 & RAMOS, J. E. F.; & O insólito e a física moderna: interfaces didáticas do \\
\hline
\end{tabular}




\begin{tabular}{|c|c|l|l|}
\hline & \multicolumn{1}{|c|}{ PIASSES, L. P. } & conto fantástico \\
\hline 17 & 2018 & $\begin{array}{l}\text { SILVA, R. } \\
\text { CONCEIÇÃO DA. }\end{array}$ & $\begin{array}{l}\text { Ensino de física moderna em um processo de sala de } \\
\text { aula invertida: reflexões e potencialidades }\end{array}$ \\
\hline 18 & $2018 \begin{array}{l}\text { SILVA, D. R. DAS; } \\
\text { SALES, C. DA; } \\
\text { PEREIRA, B.B. }\end{array}$ & $\begin{array}{l}\text { Uma proposta de abordagem temática envolvendo } \\
\text { relatividade e GPS: aspectos da natureza da ciência e } \\
\text { relação ciência e tecnologia. }\end{array}$ \\
\hline 19 & 2018 & $\begin{array}{l}\text { MUNIZ, D. S. SILVA } \\
\text { et al. }\end{array}$ & $\begin{array}{l}\text { Proposta metodológica sobre o efeito fotoelétrico para } \\
\text { o ensino médio }\end{array}$ \\
\hline 20 & 2019 & MERLIM, R. S. et al. & $\begin{array}{l}\text { Unidade de ensino potencialmente significativa: análise } \\
\text { da aplicação sobre efeito fotoelétrico }\end{array}$ \\
\hline
\end{tabular}

Fonte: Própria (2021).

Com base na descrição no item anterior, alguns partem da concepção interdisciplinar apontada na BNCC e das habilidades e competências, assim, servindo de base para a elaboração de projetos que visam o desenvolvimento do aluno, por exemplo, trabalhos voltados para Literatura e Ciência (GOMES; et al. 2010; RAMOS; PIASSI, 2017; GOMES, 2011; PAGLIARINI e ALMEIDA, 2012), tais abordagens fornecem caminhos para criatividade e novas metodologias.

Em contrapartida, há produções que abordam sobre produtos educacionais, propostas didáticas e sequências didáticas, que lideram as propostas dos trabalhos (SILVA, 2018; MUNIZ, 2018; EBERHARDT et al., 2017; MELHORATO; NICOLI, 2012; BATISTA; SIQUEIRA, 2017; SHITTER; MOREIRA, 2016; MARTINS et al., 2017; SILVA e SALES et al., 2018; SHIINO et al., 2013; CARUSO e FREITAS, 2009), com fundamentação teórica voltada para SEA, Aprendizagem significativa, UEPS, Sala de aula invertida e Metodologias ativas.

Outros métodos utilizados: a Física no cotidiano, os simuladores computacionais, atividades experimentais e proposta de inserção de FMC (JUNIOR e A. CRISTINA, 2013; SHEIREIBER et al., 2016; LOPES et al., 2017; SOARES et al., 2015, SILVEIRA e GIRARDIR, 2017), utilizando de fundamentações teóricas, tais como, a sociointerativa de Vygotsky, SEA: transposição didática, ferramenta de modelização e a aplicabilidade da física na sociedade.

Os autores abordaram as seguintes temáticas: Relatividade Restrita, Quantização da energia, modelo corpuscular da luz, condução de eletricidade em sólidos, Física Solar, Física nuclear, Física de partícula, Espectroscopia, Radioatividade, Introdução a Física Quântica, Laser de Rubi, Raios-X, Modelos atômicos e sobre a luz (Newton e Huygens), Efeito Fotoelétrico, Dilatação espaço tempo de Einstein. Esses tópicos de FMC citados fazem parte da Lista Consensual estruturada pela comunidade brasileira de físicos, Ostermann e Moreira 
(1998), pesquisadores e professores na área de física (JÚNIOR; CRUZ, 2013).

Em síntese, identificou-se na pesquisa em Ensino de FMC inúmeros trabalhos, em maioria, voltados para o aperfeiçoamento de novas didáticas; discussões sobre formação de professor; uso de tecnologia no ensino; inserção da FMC na educação básica; discussões sobre Letramento Científico e ACT. Tais questões estão fundamentadas para o desenvolvimento do saber científico, conhecimento intelectual e senso crítico do aluno. Considerando essas indagações, alavancaram-se as quantidades de trabalhos que abordam a FMC, abrindo caminhos para diferentes abordagens, metodologias e concepções, também, a preocupação do avanço da ciência e é notória a narrativa de inovação e atualização curricular.

\section{CONCLUSÕES}

A grande questão sobre a BNCC e seu compromisso com a educação, de modo geral, é um tema debatido devido a sua influência nas diretrizes do currículo. A BNCC, PCN + Ensino Médio e as outras diretrizes devem estar em consonância com a realidade e com a prática docente, pois é necessário trabalhar em conjunto para que os resultados sejam satisfatórios. Os docentes necessitam de produtos educacionais, condições materiais, sólida formação acadêmica e uma compreensão crítica da realidade das escolas públicas, pois o currículo real se faz quando não apenas é necessário definir habilidades e competências.

Nota-se que argumentos em favor da inserção de FMC condizem com a necessidade de entender o papel da ciência na sociedade e como as tecnologias atuais são essenciais. Pois, compreende-se que através dos estudos científicos foi possível evoluir tecnologicamente, além de promover bem-estar para sociedade. Assim, através da análise dos artigos foi possível evidenciar a diversidade das metodologias para a inserção de FMC, e compreender a ideia de atualização do currículo. Diante disso, encontram-se trabalhos que servem como apoio na prática docente, como também projetos que foram desenvolvidos e tiveram êxitos para a aprendizagem dos estudantes.

Tais produções evidenciaram a relevância do estudo sobre FMC no EM. Em sua maioria estavam em consonância com BNCC e PCN + em relação ao desenvolvimento de habilidades e competências etc. Logo, conclui-se que os estudos sobre a inserção de FMC proporcionarão à juventude acesso aos conhecimentos tecnológicos e científicos com diferentes metodologias e contextos. Portanto, abordar tópicos de FMC no EM é de suma importante para que os discentes entendam a Física como uma construção humana, uma área em evolução, compreendendo a relação das tecnologias atuais com o desenvolvimento do conhecimento físico. Logo, as produções acadêmicas contribuem de forma significativa para o Ensino de 
FMC, uma vez que, trazem métodos, aplicações e alternativas.

Por fim, é perceptível que alguns trabalhos introduzem ideias já discutidas por Ostermann e Moreira (2000), e discussões acerca da análise sobre as diretrizes previstas nos PCN 's + Ensino Médio (2002) que se refere à Física. Diante disso, foi possível evidenciar trabalhos "atuais", com discussões, implicações, justificativas e indagações análogas a outros trabalhos de anos atrás, logo implica que o Ensino de Física ainda passará por grandes desafios diante da realidade educacional.

\section{REFERÊNCIAS}

BATISTA, C. A.S.; SIQUEIRA, M. R. P. A inserção da Física Moderna e Contemporânea em ambientes reais de sala de aula: uma sequência de ensino-aprendizagem sobre a radioatividade. Caderno Brasileiro de Ensino de Física, Florianópolis, v. 34, n. 3, p. 880902, dez. 2017.

BARDIN, L. (1977). Análise de Conteúdo. Lisboa. Edições, 70, 225

BRASIL. Base Nacional Comum Curricular: Ensino Médio. Brasília: MEC/Secretaria de Educação Básica, 2017.

Ministério da Educação (MEC), Secretaria de Educação Média e Tecnológica (Semtec). PCN + Ensino Médio: orientações educacionais complementares aos Parâmetros Curriculares Nacionais - Ciências da Natureza e suas Tecnologias. Brasília: MEC, 2002.

CARUSO, F.; FREITAS, N de. Física Moderna no Ensino Médio: o espaço-tempo de Einstein em tirinhas. Caderno Brasileiro de Ensino de Física, Florianópolis, v. 26, n. 2, p. 355-366, ago. 2009. ISSN 2175-7941.

DOMINGUINI, L.; MAXIMIANO, J. R.; CARDOSO, L. Novas abordagens do conteúdo Física Moderna no Ensino Médio Público do Brasil. In: IX ANPED SUL: Seminário de Pesquisa em Educação da Região Sul, 2012. Universidade de Caxias do Sul.

EBERHARDT, D. et al. Experimentação no Ensino de Física Moderna: efeito fotoelétrico com lâmpada néon e LEDs. Caderno Brasileiro de Ensino de Física, Florianópolis, v. 34, n. 3, p. 928-950, dez. 2017. ISSN 2175-7941.

FRANCO, L. G.; MUNFORD, D. Reflexões sobre a Base Nacional Comum Curricular: Um olhar da área de Ciências da Natureza. Horizontes, [S.1.], v. 36, n. 1, p. 158-171, abr. 2018.

GOMES, E. F; AMARAL, S. C.; PISSI, L.P.C Máquina do tempo de H.G. WELLS: uma possibilidade de interface entre ciência e literatura no ensino de física. REMPEC - Ensino, Saúde e Ambiente, v. 3 n 2 p.144-154. Agosto, 2010.

GOMES, E. F. O Romance e a Teoria da Relatividade: A interface entre a Literatura e Ciência no Ensino de Física através do discurso e da estrutura da ficção. São Paulo: Faculdade de Educação, Instituto de Física, Instituto de Química, Instituto de Biociências, Universidade de São Paulo, 2011. 155 p. Dissertação de Mestrado em Ensino de Ciências. 
JUNIOR, P. C.; A. CRISTINA, C. C. S. Parceria entre a educação formal e não formal visando inovações curriculares: o Ensino de Física moderna a partir da física solar. In: IX CONGRESO INTERNACIONAL SOBRE INVESTIGACIÓN EN DIDÁCTICA DE LAS CIENCIAS, 2013.p. 786-790.

MARTINS, C.O.; PARISOTO, M. F.; HEIMFARTH, T.; ZARA, R. A.; LEONEL, A. A. O ensino de relatividade restrita no ensino médio a partir de uma unidade de ensino potencialmente significativa. In: X CONGRESO INTERNACIONAL SOBRE INVESTIGACIÓN EN DIDÁCTICA DE LAS CIENCIAS (2017), p. 1209-1214.

MELHORATO, R. L.; NICOLI, G. T. Da física clássica à moderna: o simples toque de uma sirene. Rev. Bras. Ensino Fís., São Paulo. v. 34, n. 3, p. 1-4, 2012.

MERLIM, R. S. et al. Unidade de ensino potencialmente significativa: análise da aplicação sobre efeito fotoelétrico. Revista Thema, [S.I.], v. 16, n. 2, p. 284-300, jul. 2019.

MOREIRA, M. A. Uma análise crítica do ensino de Física. Estud. av., São Paulo, v. 32, n. 94, p. 73-80, Dez. 2018.

MOZENA, E. R.; OSTERMANN, F. Editorial: Sobre a Base Nacional Comum Curricular (BNCC) e o Ensino de Física. Caderno Brasileiro de Ensino de Física, Florianópolis, v. 33, n. 2, p. 327-332, set. 2016. ISSN 2175-7941.

MUNIZ, D. S. SILVA, A. J. SILVA, J.P.C. NASCIMENTO, D. O. Proposta metodológica sobre o efeito fotoelétrico para o ensino médio. Rev Cient da Fac Educ e Meio Ambiente: Revista da Faculdade de Educação e Meio Ambiente - FAEMA, Ariquemes, v. 9, n. 2, p. 841-845, jul.-dez. 2018.

KIKUCHI, L. A.; ORTIZ, A. J. BATISTA, I. L. Ensino de Física Moderna e Contemporânea no Ensino Médio: Uma análise do que se tem discutido a respeito do assunto. Encontro Nacional de Pesquisa em Educação em Ciências - IX ENPEC, Águas de Lindóia -SP. 2013.

LEONEL, A. A. SOUZA, C. A. Nanociência e Nanotecnologia para o Ensino de Física Moderna e Contemporânea na perspectiva da Alfabetização Científica e Técnica. Encontro Nacional de Pesquisa em Educação em Ciência, Florianópolis, nov. 2009.

LOPES, E.V. BELLUCCO, A. GAULKE, A. M. CALEGARI, M. H. Como se aproximar do invisível: o uso dos modelos no ensino da física moderna para alunos do ensino médio. XXII Simpósio Nacional de Ensino de Física - SNEF 2017.

OSTERMANN, F.; MOREIRA, M. A. Uma revisão bibliográfica sobre a área de pesquisa "Física Moderna e Contemporânea no Ensino Médio". Investigações em Ensino de Ciências, Porto Alegre, v. 5, n. 1, p. 23-48, jan. 2000.

PAGLIARINI, C. R; ALMEIDA, M. J. P. M. Produção de sentidos numa leitura de divulgação científica sobre física quântica no ensino médio. In: XV Encontro de Pesquisa em Ensino de Física - Maresias - 2014. 
PENA, FÁBIO LUÍS ALVES. Por que nós, professores de Física do Ensino Médio, devemos inserir tópicos e ideias de física moderna e contemporânea na sala de aula? Rev. Bras. Ensino Fís., São Paulo, v. 28, n. 1, p. 1-2, 2006.

PEREIRA, A. P.; OSTERMANN, F. Sobre o ensino de física moderna e contemporânea: uma revisão da produção acadêmica recente. Investigações em Ensino de Ciências - V14(3), pp. 393-420, 2009.

RAMOS, J. E. F.; PIASSI, L. P. O insólito e a física moderna: interfaces didáticas do conto fantástico. Ciênc. educ. (Bauru), Bauru, v. 23, n. 1, p. 163-180, Mar. 2017.

SALINAS, S. R. A. A física do século XX. Estud. av., São Paulo, v. 24, n. 68, p. 369-374, 2010.

SELLES, S. E. Editorial: A BNCC e a resolução de CNE/CP no 2/2015 para a formação docente: a "carroça na gente dos bois". Caderno Brasileiro de Ensino de Física, v. 33, n. 3, p. 689-701, ago. 2018.

SILVA, R. CONCEIÇÃO DA. Ensino de física moderna em um processo de sala de aula invertida: reflexões e potencialidades. Horizontes - Revista de Educação, [S.l.], v. 6, n. 12, p. 141-153, dez. 2018.

SILVA, J. R. N.; ARENGHI, L. E.B.; LINO, A. Por que inserir física moderna e contemporânea no ensino médio? Uma revisão das justificativas dos trabalhos acadêmicos. R. B. E. C. T., vol 6, núm. 1, jan-abr.2013.

SILVA, D. R. DA; SALES, C. DA; PEREIRA, B. B. Uma proposta de abordagem temática envolvendo relatividade e GPS: aspectos da natureza da ciência e relação ciência e tecnologia. In: XVII Encontro de Pesquisa em Ensino de Física, Campos do Jordão -SP, 2018.

SILVEIRA, SÉRGIO; GIRARDI, MAURICIO. Desenvolvimento de um kit experimental com Arduino para o Ensino de Física Moderna no Ensino Médio. Rev. Bras. Ensino Fís., São Paulo, v. 39, n. 4, e4502, 2017.

SHIINO, H. S.; WATANABE, G.; RIZZATTO, C.M.; CARAMALLO, G.W.; uma proposta para sala de aula sobre a física nuclear e a física de partículas. In: XX Simpósio Nacional de Ensino de Física - SNEF, São Paulo, SP, 2013.

Schitter, Daniela e Moreira, M. A. Física Moderna e Contemporânea no primeiro ano do Ensino Médio: Laser de Rubi um exemplo de Unidade de Ensino Potencialmente Significativa. R. bras. Ens. Ci. Tecnol., Ponta Grossa, v. 9, n. 3, p. 1-24, mai./ago. 2016

Schreiber, S. C., Stori, A., Camargo, S., Hilger, T. R., \& Samojeden, L. L. (2016). Desenvolvendo atividades sobre a produção de raios $\mathrm{x}$ em aulas de física no ensino médio. In Atas do XVI Encontro de Pesquisa em Ensino de Física. Natal, RN.

SOARES, A. A.; MORAES, L. E.; OLIVEIRA, F. G. Ensino de matéria e radiação no ensino médio com o auxílio de simuladores interativos. Caderno Brasileiro de Ensino de Física, Florianópolis, v. 32, n. 3, p. 915-933, jun. 2015. ISSN 2175-7941. 
RODRIGUES, et al.

TENFEN, D. N. Editorial: Base Comum Curricular (BNCC). Caderno Brasileiro de Ensino de Física, v. 33, n.1, 2016. https://doi.org/10.5007/2175-7941.2016v33n1p1. 